Sal i ne- fi I l ed I apar oscopi c surgery: A basi c st udy on partial hepat ect ony i $n$ a $r$ abbi $t$ model

\begin{tabular}{|l|l|}
\hline 著者 & $\begin{array}{l}\text { Shi mada Nasanar i , Kawaguchi Nasahi ko, I shi kawa } \\
\text { Nor i hi ko, Wat anabe Go }\end{array}$ \\
\hline $\begin{array}{l}\text { j our nal or } \\
\text { publ i cat i on t i t I e }\end{array}$ & $\begin{array}{l}\text { M ni mal I y I nvasi ve Ther apy and Al I i ed } \\
\text { Technol ogi es }\end{array}$ \\
\hline vol une & 24 \\
\hline number & 4 \\
\hline page r ange & 218 225 \\
\hline year & $2015-07-01$ \\
\hline URL & ht t p: //hdl . handl e. net /2297/43051 \\
\hline
\end{tabular}




\section{Saline-Filled Laparoscopic Surgery: A Basic Study on Partial Hepatectomy in Rabbit Model}

Short Title: Saline-filled laparoscopic surgery

Masanari Shimada, MD, Masahiko Kawaguchi, MD, PhD, Norihiko Ishikawa, $\mathrm{MD}, \mathrm{PhD}$, and Go Watanabe, $\mathrm{MD}, \mathrm{PhD}$

From the Department of General and Cardiothoracic Surgery, Kanazawa University School of Medicine

Corresponding author: Masanari Shimada, MD , Department of General and Cardiothoracic Surgery, Kanazawa University School of Medicine, 13-1 Takaramachi, Kanazawa 920-8641, Japan

Tel: +80762652222

Fax: +80762226833

E-Mail: masanari.shimada@gmail.com

\section{Abstract}

\section{Background}

There is still a poor understanding of the effects of pneumoperitoneum with insufflation of carbon dioxide gas $\left(\mathrm{CO}_{2}\right)$ on malignant cells, and pneumoperitoneum has a negative impact on cardiopulmonary responses. A novel saline-filled laparoscopic surgery (SAFLS) is proposed, and the technical feasibility of performing saline-filled laparoscopic partial hepatectomy (LPH) was evaluated in a rabbit model.

\section{Methods}

Twelve LPH were performed in rabbits, with 6 procedures performed using an ultrasonic device with $\mathrm{CO}_{2}$ pneumoperitoneum $\left(\mathrm{CO}_{2}\right.$ group) and 6 
procedures performed using a bipolar resectoscope (RS) in a saline-filled environment (Saline group). Resection time, $\mathrm{CO}_{2}$ and saline consumption, vital signs, blood gas analysis, complications, interleukin-1 beta (IL-1B) and C-reactive protein (CRP) levels were measured. The effectiveness of the resections was evaluated by the pathological findings.

\section{Results}

LPH was successfully performed with clear observation by irrigation and good control of bleeding by coagulation with RS. There were no significant differences in all perioperative values, IL-1 $\beta$ and CRP levels between the two groups. All pathological specimens of the Saline group showed that the resected lesions were coagulated and regenerated as well as in the $\mathrm{CO}_{2}$ group.

\section{Conclusions}

SAFLS provides a good surgical view with irrigation and identification of bleeding sites with the feasibility.

\section{Keywords}

laparoscopic surgery

saline

hepatectomy

rabbit model

resectoscope

\section{Introduction}

In recent years, laparoscopic surgery has been performed in almost every field of surgery because it has been demonstrated to be less invasive [1]. In the past, materials such as helium, nitrous oxide, and argon have been discussed as candidates for use as insufflation agents to expand the intraluminal cavity and secure the operative field [2]. 
Currently, creating a pneumoperitoneum with an insufflation of carbon dioxide gas $\left(\mathrm{CO}_{2}\right)$ has become the mainstream. $\mathrm{CO}_{2}$ is inexpensive, noncombustible, and colorless. Furthermore, it is excreted by the lungs during normal respiration, and it is highly soluble in water, which reduces the risk of gas embolism, which would impair cardiac function [3]. However, insufflation of gas into the abdominal cavity produces conditions similar to open surgery, since organs are exposed to dry, cold gas [4], and surgical fields are affected by gravity. There have also been reports of a few complications of gas embolism [5-8]. Although laparoscopic surgery for advanced cancer has recently been introduced with positive results, the effect of $\mathrm{CO}_{2}$ gas on organs and malignant cells is not yet entirely clear [9-17]. Thus, we cannot be certain that $\mathrm{CO}_{2}$ is a completely benign physiological substrate. Some animal studies have shown that a $\mathrm{CO}_{2}$ pneumoperitoneum may actually stimulate metastases, thus, $\mathrm{CO}_{2}$ pneumoperitoneum still must be examined carefully in cases of "advanced" malignant tumor [13-17]. Currently, we expect "normal saline solution" to be a more ideal material for the next generation to counter these problems. Several articles have reported on laparoscopic and endoscopic procedures that fill the body cavity with fluid. In 1987, Raatz [18] reported laparoscopy with artificial ascites for diagnostic purposes. In 2003, Abdalla et al. [19] also reported laparoscopic observation by instilling normal saline into the abdominal cavity. To date, endoscopic surgery of the urinary tract, joints, or gynecological organs has commonly been carried out and has achieved good results. The key benefits of a saline-filled operative field are: the organs can be kept at an optimum temperature and humidity; venous bleeding is controlled with hydrostatic pressure; the bleeding point is easily visible; interruption by halation (due to strong reflected light) or loss of transparency is less common; and buoyancy maintains the surgical field in a natural state. The development of a new navigation system with a combination of ultrasonography and endoscopy is expected [20,21]. Furthermore, in the future, SAFLS may be applicable to operations in zero gravity, such as on a space station [22]. Igarashi et al. [23] reported that laparoscopic cholecystectomy using an instillation of sorbitol solution was successfully undertaken in a porcine model. Therefore, our first procedure in which a laparoscopic partial hepatectomy was performed with normal saline solution (SAFLS) replacing $\mathrm{CO}_{2}$ in a rabbit model with a focus on laparoscopic hepatectomy, cases of which have been increasing, is reported. 


\section{Materials and Methods}

\section{Laparoscopic partial hepatectomy model in rabbits}

Twelve partial hepatectomies were performed in New Zealand white female rabbits weighing 2.5-3.0 kg, with 6 procedures performed using an ultrasonic device with traditional $\mathrm{CO}_{2}$ pneumoperitoneum $\left(\mathrm{CO}_{2}\right.$ group) and 6 procedures performed using a bipolar resectoscope in a saline-filled environment (Saline group). The study protocol was approved by the Institute for Animal Experimentation, Kanazawa University Advanced Science Research Center. Anesthesia was induced with an intramuscular injection of $30 \mathrm{mg} / \mathrm{kg}$ ketamine and inhalation of $1 \%$ halothane, and it was maintained with continuous inhalation of $0.5 \%$ halothane and intramuscular injection of diazepam $1.5 \mathrm{mg} / \mathrm{kg}$ and $1 \%$ lidocaine as local anesthesia. The rabbits underwent surgical intervention in a horizontal supine position. A cathode ray tube display (OEV-203; Olympus Medical Systems, Tokyo, Japan), a video system center (OTV-SP1C; Olympus), and a light source (CLV-S40; Olympus) were prepared for laparoscopic monitoring. A 3-cm-diameter mini laparotomy was performed in the epigastric region. A single incisional laparoscopic port (EZ access; Hakko, Nagano, Japan) was applied to the incision, and a 12-mm trocar (XCEL; Ethicon, Tokyo, Japan) and a 5-mm trocar (Hakko, Nagano, Japan) were set up on the EZ access port (Fig.1).

\section{Saline-filled laparoscopic surgical procedure}

At first, a silicon seat was inserted below the liver in order to hold in the omentum and small bowel. Normal saline solution kept at $40^{\circ} \mathrm{C}$ was used to fill the abdominal cavity, and the EZ access port was sealed. The Bipolar Resectoscope (RS; Karl Storz, Tuttlingen, Germany) fitted with an electrode pointed top (K27040 BLV, Karl Storz) was used for the partial left lobe resection with irrigation and drainage of the saline via the RS. Because the RS has a return electrode within the sheath, it does not require a patient plate. To irrigate the saline, 2-L saline bottles (Fuso Pharmaceutical Industries, Ltd., Osaka, Japan) were hung up and connected to the RS. The intra-abdominal pressures of rabbits were kept at $0-5 \mathrm{mmHg}$ as a result of spontaneous drainage from the 
trocars. The VIO300D electrosurgical generator (ERBE USA, Inc., Marietta, Georgia, USA and AMCO, Tokyo, Japan) was used for bipolar cutting and bipolar soft coagulation (Fig.1). High-frequency current controlled by the VIO300D passed through an active electrode to the sheath electrode without peripheral spread. The RS was inserted into the abdominal cavity through a 12-mm trocar. On the other hand, laparoscopic forceps were inserted through a 5-mm trocar to grasp the edge of the liver. The resected specimen was removed through the epigastric incision. The filled saline was drained as much as possible, and all rabbits recovered from anesthesia.

\section{Traditional surgical procedure with $\mathrm{CO}_{2}$ pneumoperitoneum}

In the $\mathrm{CO}_{2}$ group, rabbits were operated on in the same setting as used for the Saline group. Rabbits underwent conventional $\mathrm{CO}_{2}$ pneumoperitoneum at $8-10 \mathrm{mmHg}$. A 10-mm, 30-down, 2-dimensional camera (A5295A; Olympus Medical Systems, Tokyo, Japan) was prepared for laparoscopic monitoring. Sonosurg-G2 and T3905 scissors (Olympus Medical Systems) were used for the partial left lobectomy. As in the saline group, the resected specimen was removed through the epigastric incision.

\section{Data collection and measurements}

In the perioperative period, resection time, $\mathrm{CO}_{2}$ and saline consumption, vital signs (heart rate and body temperature), arterial blood gas analysis, hemoglobin ( $\mathrm{Hb})$ level, and complications were recorded. Blood pressure estimation was not included, because it was extremely difficult to measure the rabbits' blood pressure. One-milliliter blood samples were collected from the ear vein immediately before the operation, 1 hour after the surgery, and on postoperative days 1, 3, and 7. The blood samples were stored at $-25^{\circ} \mathrm{C}$. The serum concentrations of IL- $1 \beta$ and C-reactive protein (CRP) were measured using enzyme-linked immunosorbent assay (ELISA) kits (Quantikine ${ }^{\circledR}$ ELISA; R\&D systems, Inc, Minneapolis, MN, USA, and Rabbit CRP ELISA KIT AKRCR-017; Shibayagi Co., Ltd., Gunma, Japan). Necropsy was performed in early death cases and surviving cases on postoperative days 7,14 , and 21 . Histological examinations were then performed to evaluate the resected site and the liver's healing process. 


\section{Statistical analysis}

The Graphpad Prism for Mac OS X ver.5.0 (GraphPad Software, Inc., San Diego, CA, USA) was used for statistical analysis. The results are presented as means \pm standard deviation (SD), and two way analysis of variance (ANOVA) was used. Comparison of the resection time was performed by a $t$-test, and the log-rank test was used to compare survival curves between the two groups. All $P$-values less than 0.05 were considered significant.

\section{Results}

Intraoperative findings during SAFLS

Figure 2 and the supplemental video illustrate the surgical process for SAFLS. After normal saline solution filled the abdominal cavity, the RS was inserted through the 12-mm trocar, and the abdominal cavity was observed. Left-handed forceps inserted through the 5-mm trocar could easily change the axis of the tissue because of buoyancy. The resection was started from the edge while flicking the electrode pointed top of the RS in and out with the "CUT" mode of the VIO300D electrosurgical generator (Fig.2 A). Although some bleeding was observed on the way, the bleeding could be stopped rapidly using the "SOFT COAG" mode (Fig.2 B, C). Thus, in the surgical field filled with normal saline solution, hepatic parenchymal resection could be performed uneventfully with the RS while identifying and dealing with bleeding points successfully (Fig.2 D).

\section{Perioperative measurements}

Table 1 compares the perioperative measurements between the Saline group and the $\mathrm{CO}_{2}$ group. Resection time, vital signs, hemoglobin level, and respiratory function were not significantly different between the groups. The mean $\mathrm{CO}_{2}$ consumption was $18.9 \mathrm{~L}$, and the mean saline volume was $3592 \mathrm{~mL}$. There were no intraoperative complications in either group. At necropsy, an abdominal wall abscess was apparent in 1 case in the $\mathrm{CO}_{2}$ group, but no complications were found in the Saline group. The postoperative 
survival rate was significantly higher in the Saline group than in the $\mathrm{CO}_{2}$ group $(P=$ 0.0178). Only one case in the Saline group died (on postoperative day 2), but 5 cases died within 2 days after the procedure in the $\mathrm{CO}_{2}$ group.

\section{Table 1. Perioperative data}

\begin{tabular}{|c|c|c|c|}
\hline Parameters & $\mathrm{CO}_{2}$ Group $(\mathrm{n}=6)$ & Saline Group $(n=6)$ & $P$ value \\
\hline $\begin{array}{l}\text { Resection time }(\mathrm{min}) \\
(\text { mean } \pm \mathrm{SD})\end{array}$ & $5.6 \pm 2.3$ & $9.8 \pm 1.4$ & 0.3078 (ns) \\
\hline Consumption of $\mathrm{CO}_{2}(\mathrm{~L})$ & $18.9 \pm 6.3$ & - & - \\
\hline Consumption of Saline (ml) & - & $3592 \pm 775$ & - \\
\hline Heart Rate (beat/min) Pre / Post & $307 \pm 9 / 280 \pm 12$ & $309 \pm 14 / 287 \pm 14$ & $0.8484(\mathrm{~ns})$ \\
\hline Body Temperature $\left({ }^{\circ} \mathrm{C}\right)$ & $39.4 \pm 0.3 / 38.9 \pm 0.1$ & $39.3 \pm 0.2 / 37.3 \pm 0.9$ & $0.4273(\mathrm{~ns})$ \\
\hline $\mathrm{Hb}(\mathrm{g} / \mathrm{dl})$ & $13.4 \pm 0.5 / 13.7 \pm 0.3$ & $14.1 \pm 0.8 / 13.7 \pm 0.7$ & $0.1241(\mathrm{~ns})$ \\
\hline $\mathrm{PaO} 2$ (mmHg) & $195.0 \pm 7.5 / 175.0 \pm 10.8$ & $179.3 \pm 19.3 / 149.2 \pm 31.8$ & $0.7462(\mathrm{~ns})$ \\
\hline $\mathrm{PaCO} 2(\mathrm{mmHg})$ & $26.9 \pm 1.6 / 25.1 \pm 4.5$ & $26.1 \pm 2.7 / 29.0 \pm 2.3$ & 0.7694 (ns) \\
\hline Conversions & 0 & 0 & - \\
\hline Intraoperative complications & 0 & 0 & - \\
\hline Postoperative complications & abdominal wall abscess 1 & 0 & - \\
\hline
\end{tabular}

All perioperative values were not significantly different between the both groups

Serum IL-1 $\beta$ and CRP levels

Figure 3 compares the postoperative serum IL-1 $\beta$ and CRP levels. There were no significant differences in the IL-1 $\beta$ and CRP levels between the two groups.

Histopathologic examination of the resected site 
Figure 4 shows the histopathological findings of the resected site. The resected hepatic tissue in the Saline group was coagulated as well as in the $\mathrm{CO}_{2}$ group (Fig.4 A, C). The regenerated nodules with neutrophil aggregation were also well formed in both groups (Fig.4 B, D).

\section{Discussion}

This experimental study clearly documented that SAFLS for resecting hepatic parenchyma with RS can be performed uneventfully with successful identification and handling of bleeding points. The present study confirmed the several advantages of a saline-filled operative field: the organs are kept at an optimum temperature and humidity; venous bleeding is controlled with hydrostatic pressure; the bleeding point is easily visible; interruption by halation (due to strong reflected light) or loss of transparency is less; and buoyancy maintains the surgical field in a natural state [20,23]. Normal saline solution was specifically chosen, because nonelectrolyte isotonic solutions containing mannitol or sorbitol will cause the 'transurethral resection (TUR) syndrome' attributable to the pharmacological effects of the irrigant solutes, the volume effect of the solvent, and dilutional hyponatremia [24, 25].

The bipolar resectoscope, which was reported by Shiozawa et al. [25], is a newly developed TUR system using saline for irrigation instead of the traditional sorbitol solution in order to prevent obturator nerve reflexes or the TUR syndrome. Shiozawa et al. [25] reported that post-resection tests showed no significant anomalies relative to blood electrolyte concentrations in sorbitol solution or saline irrigation. Prior to this study, we performed experiments using Sonosurg (Olympus), Harmonic Ace (Johnson \& Johnson Co., Ltd., Tokyo, Japan), and Ligasure (Covidien Group Japan Co., Ltd., Tokyo, Japan) for cutting pieces of edible liver in the saline environment. However, all of them generated "dust" and clouded our vision. We then used the RS under the same conditions, and the RS could cut the specimen successfully. As seen from the above, the RS has enough of a track record in safe use in saline solution; it was therefore adopted in the present study.

Although $\mathrm{CO}_{2}$ pneumoperitoneum is currently predominant in laparoscopic surgery, it has both good and bad aspects and is controversial. Several studies have described the 
effects of $\mathrm{CO}_{2}$ pneumoperitoneum on intra-abdominal blood flow and reported diminished blood flow in the portal vein and the hepatic artery [26,27]. On the other hand, recent report suggests that prolonged pneumoperitoneum for about 6 hours does not hamper liver function or cause liver damage after extended laparoscopic procedures [28]. Furthermore, it is undeniable that $\mathrm{CO}_{2}$ pneumoperitoneum induces pathophysiological hemodynamic, pulmonary, renal, splanchnic, and endocrine changes [29]. According to two papers published by Chiu AW, et al [30,31], peritoneal insufflation of $\mathrm{CO}_{2}$ to a pressure of $15 \mathrm{mmHg}$ elicited transient elevations of the aortic pressure, carotid arterial blood flow, and superficial renal cortical blood flow in porcine model. Although a question that it is pressure not the $\mathrm{CO}_{2}$ and the same problem is likely to happen with saline may arise, because the intra-abdominal pressure of rabbits in SAFLS was kept at $0-5 \mathrm{mmHg}$ by natural drainage from the trocars, we think that we do not have to worry to put up such high intra-abdominal pressure.

Moreover, there have been several reports about the effects of $\mathrm{CO}_{2}$ gas on malignant cells [13-17]. Insufflation of $\mathrm{CO}_{2}$ may actually stimulate liver metastases [16]. Izumi et al. [13] reported that the intrahepatic expression of intercellular adhesion molecule-1 (ICAM-1), which is associated with the adherence of free tumor cells to the hepatic vascular endothelial surface, was higher after $\mathrm{CO}_{2}$ pneumoperitoneum. Ishida et al. [14] demonstrated that an elevated insufflation pressure facilitates the location of intraportally injected tumor cells in the liver, and that the pulmonary location of the tumor cells may not depend on insufflation pressures. It has been reported that $\mathrm{CO}_{2}$ gas or acidosis itself inhibits phagocytosis by macrophages in the abdominal cavity, and that the ability to phagocytose intraoperative free tumor cells may be suppressed [14,29]. As seen above, suppression of cytokine production by macrophages contributes to the lower invasiveness of laparoscopic surgery, but on the other hand, we should be deeply concerned that $\mathrm{CO}_{2}$ pneumoperitoneum has the potential to suppress the immune reaction against malignant cells. Recent research also indicates that the $\mathrm{CO}_{2}$ pneumoperitoneum could promote the proliferation and metastasis of human ovarian cancer in nude mice on the grounds that the expression of tumor metastasis suppressor gene (NM23-H1) in $\mathrm{CO}_{2}$ pneumoperitoneum groups was significantly lower than that in laparotomy group, in contrast to NM23-H1, matrix metalloproteinase-2 (MMP-2) expression was significantly higher in $\mathrm{CO}_{2}$ pneumoperitoneum groups than that in laparotomy group [17]. Also, pneumoperitoneum is reported to induce oxidative stress 
due to the desiccative effect of cold, dry gas insufflation. In order to solve the problem, there is data in the literature to show that warming and humidifying $\mathrm{CO}_{2}$ gas can prevent the loss of body heat and humidity from the abdominal cavity [32]. However, the results of the present study do not rule out the use of $\mathrm{CO}_{2}$ pneumoperitoneum. Instead, the results suggest that SAFLS may produce a more ideal surgical field because it avoids the adverse effects of $\mathrm{CO}_{2}$ pneumoperitoneum. However, we don't have the satisfactory data to imply this, so we need further investigation.

Since the first laparoscopic hepatectomy was reported in 1991 [33], over 2,800 cases were reported until 2008, with the majority being minor liver resections [34]. Recently, cases of major hepatectomy have accumulated [35], and there will be a gradual increase in the number of cases. However, one of the rare but non-negligible complications of laparoscopic major hepatectomy is "gas embolism". Gas embolism has been reported to occur in 1\% of laparoscopic hepatectomies [36]. Not many reports deal with gas embolism, but it is felt that a few cases of gas embolism occur, including transient intraoperative ones. It is said that even if gas embolisms occur, circulation dynamics vary only slightly [37-39], but there have been reports of death caused by gas embolism $[9,40]$. During laparoscopic liver resection in a porcine model, gas embolism was detected echocardiographically in all cases [6]. Furthermore, Takagi indicated that elevated intra-abdominal pressure over $10 \mathrm{mmHg}$ with $\mathrm{CO}_{2}$ pneumoperitoneum may cause a decrease in portal blood velocity and lead to embolism through the hepatic vein [24].

With respect to invasiveness, the perioperative changes in vital signs and inflammatory substances were evaluated. In SAFLS, it appears that the warmed saline could prevent the occurrence of hypothermia. IL-1 $\beta$ and CRP levels, which were examined in the present study, were also examined in previous reports comparing laparoscopy with open laparotomy $[1,41]$. The cytokines IL-1, tumor necrosis factor (TNF), and interleukin-6 (IL-6) are known to be major mediators of the acute phase response [42]. CRP is an acute-phase protein induced by IL-6 in hepatocytes [43]. IL-1 has been shown to induce procoagulant activity in endothelial cells, including increased release of tissue factor (TF) [44]. In a study comparing laparoscopic surgery with open surgery, the cytokine surge was correlated with hypercoagulability, and the correlation between cytokine and coagulation activation may be related to the type of surgery performed [1]. Thus, the present study seems to demonstrate the non-inferiority of 
SAFLS as compared to $\mathrm{CO}_{2}$ pneumoperitoneum with respect to invasiveness. The Saline group had a higher survival rate than the $\mathrm{CO}_{2}$ group. Some of the reasons were that the pneumoperitoneum itself increased stress for the rabbits, the pneumoperitoneum affected respiratory function, and $\mathrm{CO}_{2}$ embolism could have occurred, although other organs were not examined by thorough, detailed, histopathological examination.

Regenerated nodules of the resected liver in rabbits are produced in 3-7 days after surgery, and wide granulomatous tissue covers the resected site in a month [45]. In SAFLS, the coagulated lesion was also identified successfully, and the resected site was regenerated as well as in the $\mathrm{CO}_{2}$ group.

In the present study, some difficulties and limitations must be considered, because this study was limited to an acute-phase experiment of hepatic resection in a saline solution. The rabbit model was selected for this protocol, because it is first necessary to confirm the feasibility of SAFLS in vivo on a small-scale trial, and because we read the paper that the rabbit model has a good track record of often being used as laparoscopic surgical training to prepare surgeons for infant surgery [46]. However, intraoperative monitoring of the rabbit's blood pressure, venous return, and cardiac output is difficult. The method to monitor hemodynamic data is undocumented in the general anesthetic protocol for videolaparoscopic surgery in rabbits [47]. Also, because the amount of bleeding was extremely small, it was necessary to use measurements of the perioperative change in $\mathrm{Hb}$ to estimate the amount of bleeding. Furthermore, the range of tests conducted for biochemical examination of the blood was limited, because of the limited budget and sample volume. Indeed, we attempted our procedures in porcine model on ahead, but we couldn't carry out the experiments because the reach of the bipolar resectoscope was small in length in porcine liver. Instead, we found that the effect on instrument movement and the ability to easily was smooth and little resistance in a large animal, too. Then, we selected the rabbit model for basic study under unavoidable circumstances. However, we think that the fact we got good results in survival rate in Saline Group despite using fragile animal like rabbits is counted for a great deal.

Since studies of the biochemical effect of normal saline on peritoneum are scant, it is not possible to be certain that normal saline is absolutely physiologic. Physiological saline solution is generally-credited with safety, for example it is adopted as the main component of the peritoneal dialysis fluid for the treatment of metabolic alkalosis with 
chronic or acute renal failure [48], but there are few research to prove that normal saline is safe for the "normal" peritoneum. The future challenge is to research the effects of normal saline on the "normal" peritoneum. If major hepatectomy is done, the approach to the hepatic veins or biliary ducts is essential. Therefore, in SAFLS, troubleshooting will be required for bleeding from such major vessels in clinical practice. In addition to this, if SAFLS is to be applied to the human abdominal cavity, it will be necessary to save a large volume of saline inside the wide abdominal cavity. It will eventually become necessary to develop instruments such as trocars or a filtering apparatus to filter not only the "dust" and "cloud", but also the erythrocyte component produced in the operation. Although we also attempted to leach the drainage of fluid by the filtration membrane of an artificial heart lung apparatus, it was not possible to go as far as to filter the erythrocyte component.

In conclusion, saline-filled laparoscopic surgery with the bipolar resectoscope is safe and feasible, offering advantages such as clear vision by irrigating with the saline solution, identifying the bleeding point, and reduced retraction for organs because of buoyancy. Further research to establish an even less invasive and more ecological saline-filled surgical field is planned.

\section{Acknowledgments}

That authors would like to thank Professor A. Oe (Kanazawa University Graduate School of Medical Science Molecular and Cellular Pathology), T. Ishizuka, K. Mikami (OLYMPUS), K. Chiba, H. Komiyama, S. Kitamura (AMCO), Y. Kita (MC Medical, Inc., Tokyo, Japan), and S. Ishino (SRL, Inc., Tokyo, Japan) for providing technical support.

\section{Disclosures}

Masanari Shimada, Masahiko Kawaguchi, Norihiko Ishikawa and Go Watanabe have no conflict of interest or financial ties to disclose. 


\section{References}

1. Schietroma M, Carlei F, Mownah A, Franchi L, Mazzotta C, Sozio A, Amicucci G. Changes in the blood coagulation, fibrinolysis, and cytokine profile during laparoscopic and open cholecystectomy. Surg Endosc 2004; 18: 1090-1096.

2. Neuhaus SJ Gupta A, Watson DI. Helium and other alternative insufflation gases for laparoscopy. Surg Endosc 2001; 15: 553-560.

3. Leu WY Leow CK, Li AK. History of endoscopic and laparoscopic surgery. World J Surg 1997; 21: 444-453.

4. Huntington TR LeMaster CB. Laparoscopic hypothermia:Heat loss from insufflation gas flow Surg Laparosc Endosc 1997; 7: 153-155.

5. Schmandra TC, Mierdl S, Bauer C, Gutt C, Hanisch E. Transesophageal echocardiography shows high risk of gas embolism during laparoscopic hepatic resection under carbon dioxide pneumoperitoneum. BrJSurg 2002; 89: 870-876.

6. Jayaraman S, Kharhar A, Yang H, Bainbridge D, Quan D. The association between central venous presseure, pneumoperitoneum, and venous carbondioxide embolism in laparoscopic hepatectomy. Surg Endosc 2009; 23:2369-2373.

7. Yacoub OF, Cardona IJR, Coveler LA, Dodson MG. Carbon dioxide embolism during laparoscopy. Anesthesiology 1982; 57: 533-535.

8. Lantz PE Smith JD. Fatal carbon dioxide embolism complicating attempted laparoscopic laparoscopic cholecystectomy : Case report and literature review. J Forensic Sci 1994; 39: 1468-1480.

9. Samli MM, Guler C, Demirbas M, Koken T. The effect of carbon dioxide pneumoretroperitoneum on free oxygen radicals in rabbit retroperitoneoscopy model. Surg Laparosc Endosc Percutan Tech 2004; 14: 153-156. 
10. Wong YT, Shah PC, Birkett DH, Brams DM. Carbon dioxide pneumoperitoneum causes severe peritoneal acidosis, unaltered by heating, humidification, or bicarbonate in a porcine model. Surg Endosc 2004; 18: 1498-1503.

11. Emir H, Akman M, Belce A, Gümüştaş K, Soylet Y. Is intestinal ischemia a risk of laparoscopy? An experimental study in rabbits. Eur J Pediatr Surg 2001; 11: 158-162.

12. Altintas F, Tunali Y, Bozkurt P, Kaya G, Uygun N, Aricioğlu F, Hacibekiroğlu M. An experimental study on the relationship of intra-abdominal pressure and renal ischemia. Middle East J Anesthesiol 2001; 16: 55-66.

13. Izumi K, Ishikawa K, Tojigamori M, Matsui Y, Shiraishi N, Kitano S. Liver metastasis and ICAM-1 mRNA expression in the liver after carbon dioxide pneumoperitoneum in a murine model. Surg Endosc 2005; 19: 1049-1054.

14. Ishida H, Yokoyama M, Murata N. Influence of laparoscopic surgery on tumor metastasis and its possible mechanisms. Surgery Frontier 2008; 15: 18-25.

15. Ishida H, Murata N, Yamada H, Nakada H, Takeuchi I, Shimomura K, Fujioka M, Idezuki Y. Pneumoperitoneum with carbon dioxide enhances liver metastasis of cancer cells implanted into the portal vein in rabbits. Surg Endosc 2000; 14: 239-242.

16. Gutt CN, Kim ZG, Schmandra T, Paulucci V, Lorenz M. Carbon dioxide pneumoperitoneum is associated with increased liver metastasis in a rat model. Surgery 2000; 127: 566-570.

17. Zhang Y, Luo X, Fan B, Chen $\mathrm{H}, \mathrm{Fu}$ A, Huang J. Effect of $\mathrm{CO}_{2}$ pneumoperitoneum on the proliferation of human ovarian cancer cell line SKOV-3 and the expression of NM23-H1 and MMP-2. Arch Gynecol Obstet 2014 Aug 21 [Epub ahead of print]

18. Raatz D. Laparoscopy with artificial ascites. Endoscopy 1987; 19: 203-204. 
19. Abdalla EK, Barnett CC, Pisters PW, Cleary KR, Evans DB, Feig BW, Mansfield PF. Subaquatic laparoscopy for staging of intraabdominal malignancy. J Am Coll Surg 2003; 196: 155-158.

20. Igarashi T, Zenbutsu S, Yamaguchi T. Echo images in PLES combined with Water-Filled Laparo-Endoscopic Surgery (WAFLES). J Japanese Association for Minimum-Incision Endoscopic Surgery 2011; 3: 87-89.

21. Schneider CM, Peng PD, Taylor RH, Dachs GW, Hasser CJ, DiMaio SP, Choti MA. Robot-assisted laparoscopic ultrasonography for hepatic surgery. Surgery 2012; 151 : 756-762.

22. Satava RM. Surgery in space. Phase I: Basic surgical principles in a simulated space environment. Surgery 1988; 103: 633-637.

23. Igarashi T, Shimomura Y, Yamaguchi T, Kawahira H, Makino H, Yu WW, Naya Y. Water-filled laparoscopic surgery (WAFLES):Feasibility study in porcine model. J Laparoendosc Adv Surg Tech A 2012; 22: 70-75.

24. Hahn RG. Fluid absorption in endoscopic surgery. Br J Anaesth 2006; 96: 8-20.

25. Shiozawa H, Aizawa T, Ito T, Miki M. A new transurethral resection system: operating in saline environment precludes obtulator nerve reflexes. J Urol 2002; 168: 2665-2667.

26. Takagi S. Hepatic and portal vein blood flow during carbon dioxide pneumoperitoneum for laparoscopic hepatectomy. Surg Endosc 1998; 12: 427-431.

27. Yoshida M, Ikeda S, Sumitani D, Takakura Y, Tokunaga M, Okajima M, Ohdan H. Alteration in portal vein blood $\mathrm{pH}$, hepatic functions, and hepatic histology in a porcine carbon dioxide pneumoperitoneum model. Surg Endosc 2010; 24:1693-1700. 
28. Hoekstra LT, Ruys AT, Milstein DM, van Samkar G, van Berge Henegouwen MI, Heger M, Verheij J, van Gulik TM. Effects of pneumoperitoneum on hepatic perfusion during laparoscopy. Ann Surg 2013; 257: 302-307.

29. Gutt CN, Kim ZG, Schemmer P, Krähenbühl, Schmedt CG. Impact of laparoscopic and conventional surgery on Kupffer cells, tumor-associated CD44 expression, and intrahepatic tumor spread. Arch Surg 2002; 137: 1408-1412.

30. Chiu AW, Chang LS, Birkett DH, Babayan RK. A porcine model for renal hemodynamic study during laparoscopy. J Surg Res 1996; 60: 61-68.

31. Chiu AW, Chang LS, Birkett DH, Babayan RK. The impact of pneumoperitoneum, pneumoretroperitoneum, and gasless laparoscopy on the systemic and renal hemodynamics. J Am Coll Surg 1995; 181: 397-406.

32. Sammour T, Mittal A, Delahunt B, Phillips AR, Hill AG. Warming and humidification have no effect on oxidative stress during pneumoperitoneum in rats. Minim Invasive Ther Allied Technol. 2011; 20: 329-337.

33. Reich H, McGlynn F, DeCaprio J, Budin R. Laparoscopic excision of benign liver lesions. Obstet Gynecol 1991; 78: 956-958.

34. Nguyen KT, Gamblin TC, Geller DA. World review of laparoscopic liver resection-2,804 patients. Ann Surg 2009; 250: 831-841.

35. Dagher I, O’Rourke N, Geller DA, Cherqui D, Belli G, Gamblin TC, Lainas P, Laurent A, Nguyen KT, Marvin MR, Thomas M, Ranvindra K, Fielding G, Franco D, Buell JF. Laparoscopic major hepatectomy. Ann Surg 2009; 250: 856-860

36. Biertho L, Waage A, Gagner M. Laparoscopic hepatectomy. Ann Chir 2002; 127: 164-170. 
37. Koffron AJ, Auffenberg G, Kung R, Abecassis M. Evaluation of 300 minimally invasive liver resections at a single institution: Less is more. Ann Surg 2007; 246: 385-392.

38. Buell JF, Thomas MT, Rudich S, Marvin M, Nagubandi R, Ravindra KV, Brock G, McMasters KM. Experience with more than 500 minimally invasive hepatic procedures. Ann Surg 2008; 248: 475-486.

39. Bryant R, Laurent A, Tayer C, Cherqui D. Laparoscopic liver resection-understanding its role in current practice: The Henri Mondor Hospital experience. Ann Surg 2009; 250: 103-111.

40. Root B, Levy M. Gas embolism death after laparoscopy delayed by trapping in the portal circulation. Anesth Analg 1978; 57: 232-237.

41. Schietroma M, Carlei F, Mownah A, Franchi L, Mazzotta C, Sozio A, Lygidakis NJ, Amicucci G. A comparison of serum interleukin- 6 concentrations in patients treated by cholecystectomy via laparotomy or laparoscopy. Hepato-Gastroenterology 2004; 51: 1595-1599.

42. Perlmutter DH, Dinarello CA, Punsal PI, Colton HR. Cachectin/tumor necrosis factor regulates hepatic acute-phase gene expression. J Clin Invest 1986; 78: 1349-1354.

43. Gauldie J, Richards C, Harnish D. Interferon $\alpha 2 / B$-cell stimulatory factor type 2 shares identity with monocyte-derived hepatocyte-stimulating factor and regulates the major acute phase protein response in liver cells. Proc Natl Acad Sci 1987; 84: 7251-7255.

44. Stouthard JML, Levi M, Hack CE, Veenhof CHN, Romijin JA, Sauerwein HR, van der Poll T. Interleukin-6 stimulates coagulation, not fibrinolysis, in human. Thromb Haemostas 1996; 76: 738-743.

45. Egawa H. A basic study on wound healing after hepatic resection using a microwave tissue coagulator. J Wakayama Med Soc 1987; 38: 251-267. 
46. Simforoosh N, Khazaeli M, Nouralizadeh A, Soltani MH, Samzadeh M, Saffarian O, Rahmani J. Laparoscopic animal surgery for training without sacrificing animals; introducing the rabbit as a model for infantile laparoscopy. J Laparoendosc Adv Surg Tech A 2011; 21: 929-933.

47. Rosi PB, Manoel RMT, Fabiola SM, Ana LLM, Arlindo DRJ, Andre GN, Rodrigo DS. Anesthetic protocol for videolaparoscopic surgery in rabbits. Acta Cirurgica Brasileira 2010; 25: 121-125.

48. Inagaki Y, Miyazaki T, Amano I. Peritoneal dialysis as therapy for electrolyte and acid base disorders. Int J Artif Organs 1989; 12: 632-637.

\section{Figure Legends}

\section{Fig.1 Schema of the operation}

A 3-cm-diamater mini laparotomy incision is placed in the epigastric region. Three ports are applied to the incision on the EZ access port. To irrigate with saline, 2-L saline bottles are hung up and connected to the RS. The VIO300D electrosurgical generator is used for bipolar cutting and bipolar soft coagulation

\section{Fig.2 Intraoperative findings in SAFLS}

A: RS starts cutting the edge of the left lobe.

B, C: Although some bleeding is observed on the way, the "SOFT COAG" mode rapidly stops the bleeding.

D: The resected site is sharp and clear.

\section{Fig.3 Serum IL-1ß and CRP levels}

IL-1 $\beta$ and CRP levels are not significantly different between the groups.

\section{Fig.4 Pathological assessment}

A, C: The resected hepatic tissue in the Saline group is coagulated as well as in the $\mathrm{CO}_{2}$ 
group. (HE staining, $\times 40$ )

B, D: The regenerated nodules with neutrophil aggregation are also well formed in both groups. (HE staining, loupe) 


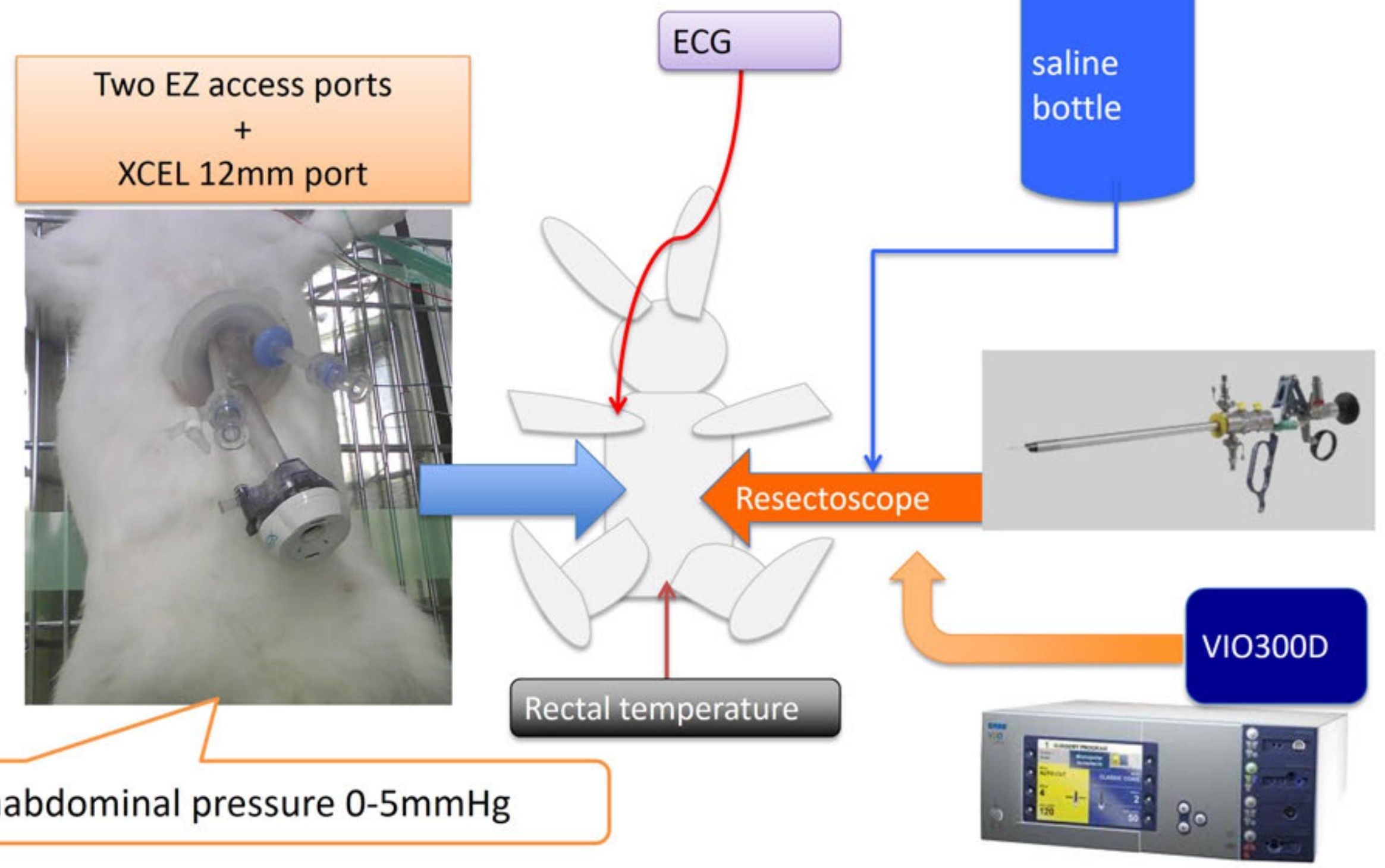




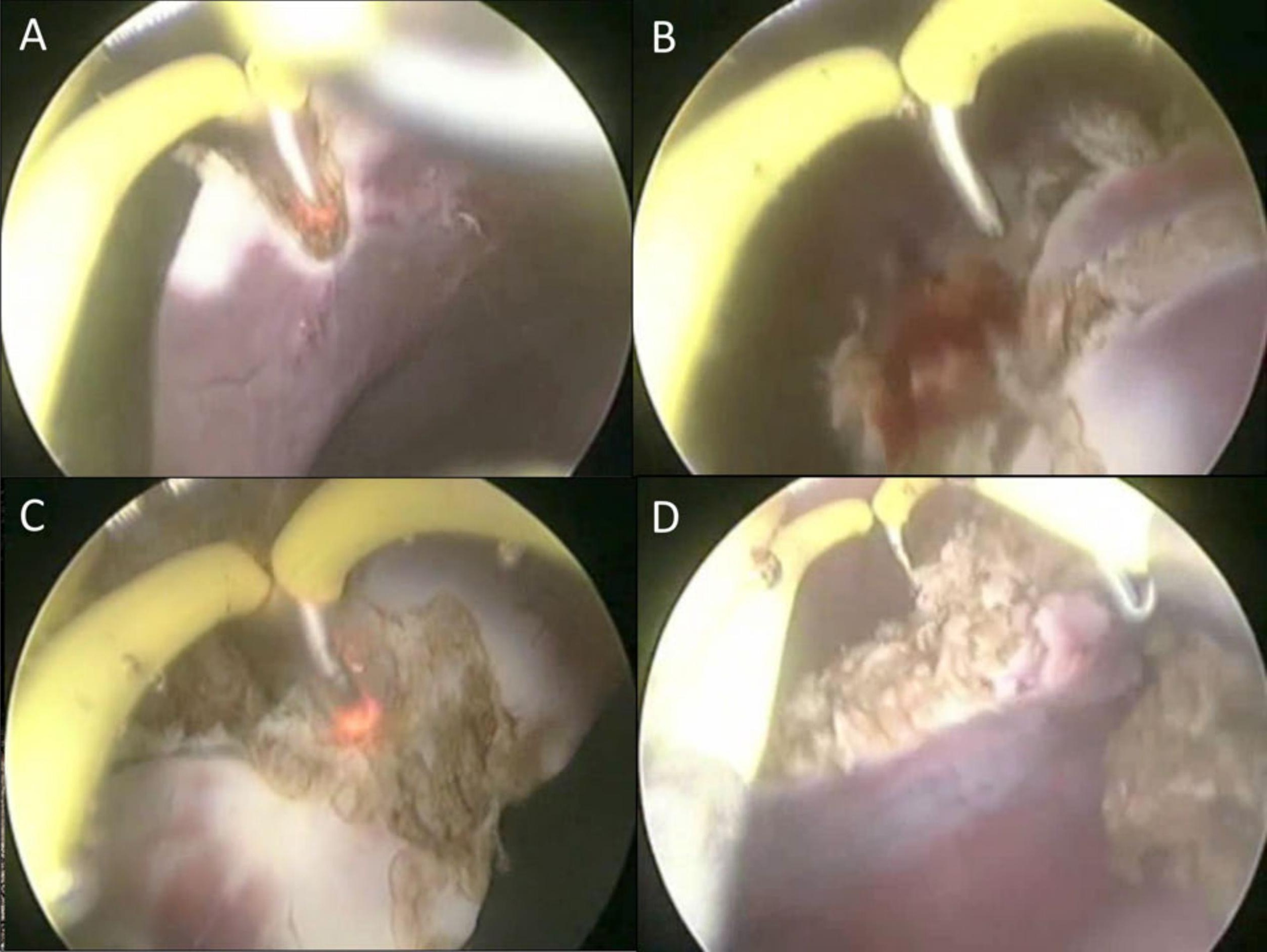



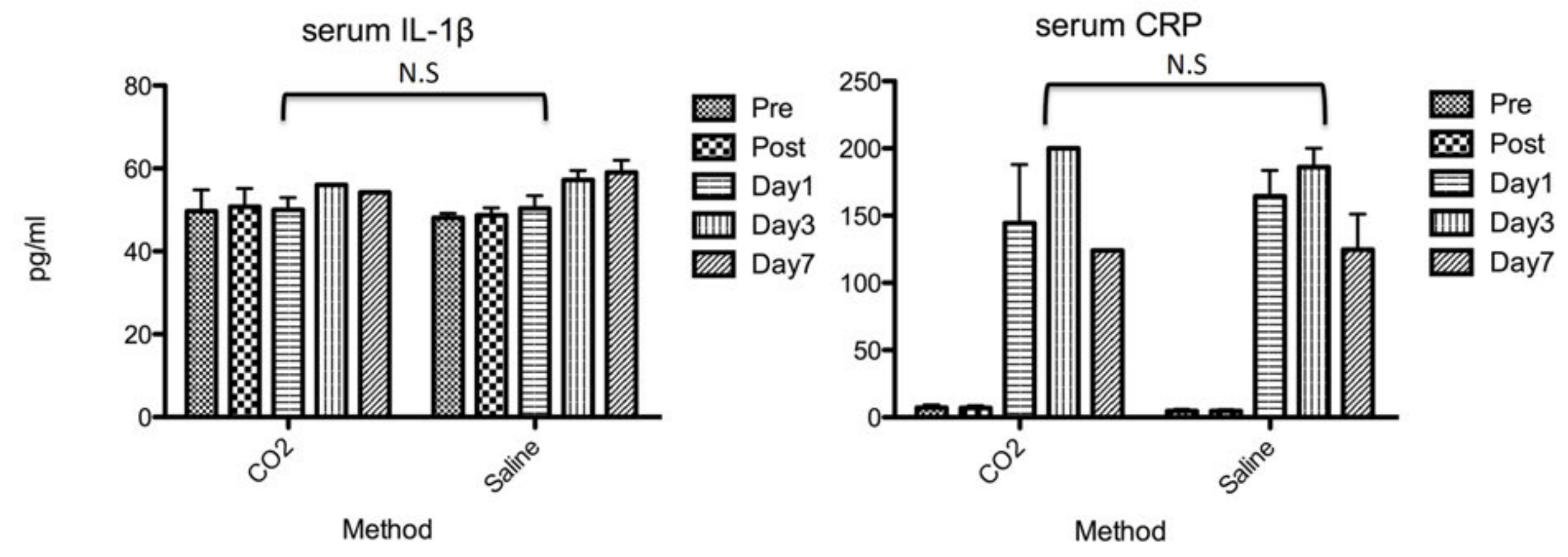


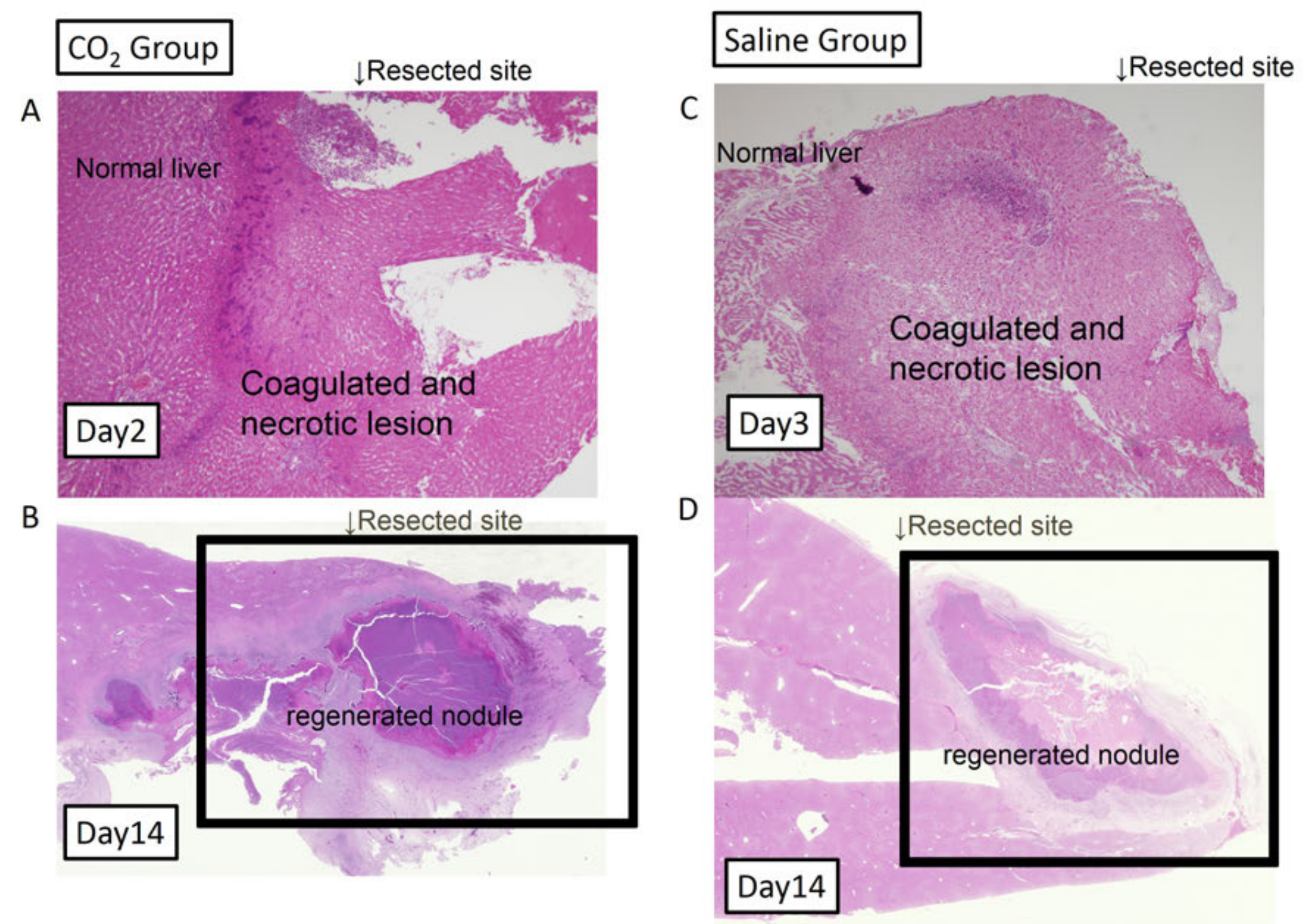

